ORIGINAL ARTICLE

\title{
Correlations of work, leisure, and sports physical activities and health status with socioeconomic factors: a national study in Israel
}

\author{
E Kahan, Y Fogelman, B Bloch
}

Postgrad Med J 2005;81:262-265. doi: 10.1136/pgmi.2004.022293

See end of article for authors' affiliations ....................

Correspondence to: Dr E Kahan, Arazim 4/7, Kfar Sava 44456, Israel; ekahan@post.tau.ac.il

Submitted 22 March 2004 Accepted 2 June 2004

\begin{abstract}
Objective: To evaluate levels of physical activities at work, leisure, and sports and to correlate them with socioeconomic and health factors.

Methods: Validated questionnaire administered to a random sample of 406 adults. Items covered demographic data, health status, smoking, and duration, frequency, intensity of physical activities. Indices of physical activity at work, leisure, and sports were analysed.

Results: Adults (both sexes) with poor self perceived health status and less than 13 years of education, regardless of their body mass index, perform no or few physical activities during their leisure time. Conclusions: The correlations of physical activity with socioeconomic and health factors differ significantly for work, leisure, and sports. Physicians should differentiate physical activities by type and intensity during anamneses.
\end{abstract}

A Ithough studies over the past 10 years have provided strong proof of the health benefits of physical activity, most of the population of the Western world continues to pursue a sedentary lifestyle. ${ }^{1-4}$ People who achieve comparatively high exertion levels during exercise are at lower risk of coronary heart disease than those with low exertion levels. ${ }^{5}$ Physical exercise may also help to prevent and manage such disease states as hyperlipidaemia, hypertension, obesity, diabetes mellitus, cancer, and osteoporosis, in addition to the age related decline in muscular strength. ${ }^{6-9}$

In a previous study ${ }^{10}$ we showed that people with a lower level of education had more physical activity at work, and that men had a higher sports index than women. Furthermore, only $1.3 \%$ of those with a high physical activity score on the self report questionnaire claimed not to engage in regular physical activity on the anamnesis type question, compared with $17.5 \%$ on those with a low questionnaire score. However, because of restrictions in the study design, we were unable to perform a regression analysis to isolate the independent impact of the risk factors examined. The aim of this national study was to evaluate the relation of background characteristics, education, and income with work, leisure, and sports related physical activities and to correlate the questionnaire results with the degree of self perceived physical activity. These findings may have important implications for identifying patients at health risk in primary care practices.

\section{METHODS}

The sample consisted of 445 men and women aged 20 to 65 years living in Israel. The participants were randomly selected from the Israeli telephone database. The interview was conducted by telephone during 2001. Interviewers were trained in two sessions of three hours each. In the first session, the principal researcher (YF) explained the questionnaire, the objective of each question, and discussed potential answers and difficulties. The second session focused on practicalities, with the interviewers acting as both (successively) interviewers and responders. The programmed length of each telephone interview was three to five minutes, as determined in a preliminary trend. Interviewers were also instructed to register the telephone number of each subject who refused to respond and, if possible, their sex and age, and the reason for refusing (I never answer telephone surveys/I don't have time now/other/no reason provided).

\section{Sample size}

The sample size was calculated to answer the question: How large a sample is needed to estimate the proportion of people who lead a sedentary lifestyle and to provide enough subjects for a multivariate analysis? In our previous study, we found that $48.2 \%$ of the sampled population of 276 people led a sedentary lifestyle; $23.2 \%$ reported low physical activity, $19.6 \%$ moderate, and $8.0 \%$ high. ${ }^{10}$ These rates were close to the $60 \%$ of people in the USA who report little or no leisure time physical activity. ${ }^{11}$ We assumed that in our population, the rate would be $50 \%$, which is also the conservative statistical option, thereby providing a margin for the detection of lower rates, like that expected for high physical activity. At a 95\% confidence level and a 10\% deviation for relative precision of the sample (that is, from 0.45 to 0.55 ), this yielded a minimum sample size of 96 , according to the formula, $N=\mathrm{Z} \quad 2 / 1-\alpha / 2 \quad \mathrm{P}(\mathrm{l}-\mathrm{P}) / 0.1^{2}$. To maintain the minimum sample size in each of the main study variables, we then multiplied this number by 4-the number of main variables (work, leisure, and sports indexes, and lifestyle categories)_obtaining a size of 386. In the event that some responders failed to answer all the questions, we increased the calculated minimum sample size by 20 (about 5\%) to 406 .

\section{Sample selection}

A large random sample of telephone numbers was collected from the Israeli telephone book. The first 406 men and women aged 20-65 years who had a good understanding of Hebrew or English constituted the study group. No other inclusion/exclusion criteria were defined during formation of the study group or at data collection.

\section{Questionnaire}

Questions on the duration, frequency, and intensity of physical activities were based on the Baecke questionnaire. ${ }^{12}$ There were also items on body weight, education, income, 
Table 1 Characteristics of the study group by index (mean (SD))

\begin{tabular}{|c|c|c|c|c|c|c|c|c|c|}
\hline \multirow[b]{2}{*}{ Variable } & \multicolumn{3}{|l|}{ Work } & \multicolumn{3}{|l|}{ Sports } & \multicolumn{3}{|l|}{ Leisure } \\
\hline & Number & Index & $p$ & Number & Index & $p$ & Number & Index & $p$ \\
\hline \multicolumn{10}{|l|}{ Age (y) } \\
\hline$<50$ & 287 & $2.64(0.81)$ & NS & 295 & $2.17(0.76)$ & 0.014 & 295 & $2.23(0.60)$ & 0.007 \\
\hline$\geqslant 50$ & 97 & $2.71(0.67)$ & & 111 & $2.38(0.84)$ & & 111 & $2.42(0.70)$ & \\
\hline \multicolumn{10}{|l|}{ Sex } \\
\hline Male & 173 & $2.7(0.81)$ & NS & 190 & $2.25(0.84)$ & NS & 190 & $2.27(0.62)$ & NS \\
\hline Female & 211 & $2.62(0.75)$ & & 216 & $2.21(0.74)$ & & 216 & $2.30(0.64)$ & \\
\hline \multicolumn{10}{|l|}{ BMI } \\
\hline$<26$ & 255 & $2.63(0.75)$ & NS & 264 & $2.30(0.78)$ & 0.016 & 264 & $2.31(0.63)$ & NS \\
\hline$\geqslant 26$ & 124 & $2.70(0.84)$ & & 137 & $2.09(0.79)$ & & 137 & $2.23(0.64)$ & \\
\hline \multicolumn{10}{|l|}{ Education (y) } \\
\hline $0-8$ & 13 & $3.17(0.79)$ & & 18 & $2.15(0.81)$ & & 18 & $2.52(0.66)$ & \\
\hline $9-12$ & 184 & $2.82(0.81)$ & $<0.001$ & 197 & $2.10(0.74)$ & 0.005 & 197 & $2.27(0.67)$ & NS \\
\hline $13+$ & 187 & $2.44(0.69)$ & & 191 & $2.36(0.82)$ & & 191 & $2.28(0.64)$ & \\
\hline \multicolumn{10}{|l|}{ Income } \\
\hline$<5000$ NIS & 215 & $2.72(0.84)$ & 0.045 & 235 & $2.12(0.77)$ & 0.011 & 235 & $2.31(0.67)$ & NS \\
\hline$\geqslant 5001 \mathrm{NIS}$ & 162 & $2.57(0.69)$ & & 163 & $2.34(0.78)$ & & 163 & $2.23(0.60)$ & \\
\hline \multicolumn{10}{|l|}{ Health* } \\
\hline 1 and 2 & 69 & $2.55(0.80)$ & & 78 & $1.92(0.70)$ & & 78 & $2.14(0.61)$ & \\
\hline 3 & 163 & $2.69(0.75)$ & NS & 172 & $2.23(0.76)$ & $<0.001$ & 172 & $2.30(0.63)$ & NS \\
\hline 4 & 152 & $2.67(0.81)$ & & 156 & $2.37(0.83)$ & & 156 & $2.34(0.65)$ & \\
\hline \multicolumn{10}{|l|}{ Smoking $†$} \\
\hline No & 272 & $2.58(0.74)$ & 0.002 & 287 & $2.29(0.81)$ & 0.009 & 287 & $2.30(0.64)$ & NS \\
\hline Yes & 112 & $2.84(0.86)$ & & 119 & $2.07(0.71)$ & & 119 & $2.24(0.61)$ & \\
\hline \multicolumn{10}{|l|}{ Symptoms (n) $\ddagger$} \\
\hline $1-2$ & 148 & $2.71(0.79)$ & & 156 & $2.29(0.73)$ & 0.009 & 156 & $2.33(0.59)$ & \\
\hline $3-5$ & 98 & $2.54(0.70)$ & NS & 104 & $2.13(0.76)$ & & 104 & $2.31(0.67)$ & NS \\
\hline $6+$ & $\begin{array}{l}70 \\
45\end{array}$ & $2.64(0.76)$ & & 51 & $1.83(0.78)$ & & 51 & $2.09(0.61)$ & \\
\hline
\end{tabular}

smoking habits, and number of symptoms, if any, during the past 30 days. The Baecke questionnaire has been frequently used as a general measure of occupational and leisure (sports and exercise related and non-sports and non-exercise related) physical activity ${ }^{13-17}$ and was found to be highly reliable and valid for both men and women. ${ }^{12}$ It is also easy to administer and to provide an accurate assessment of heavy and light intensity activities, such as walking and bicycling. ${ }^{18} 19$ For purposes of this study, we categorised the physical activities as work, leisure time, or sports related, and graded the intensity of each category according to Baecke's four item objective index. ${ }^{12}$ The first item dealt with whether the participant participates in physical activities (yes/no), and if yes, which one they perform most often (by number of hours per week, number of months per year) and second most often, if any. The second item compared the physical activity of the subject with others of the same age (much more/more/the same/less/much less physical activity), and the third item covered sweating during physical activity (very often/often/sometimes/seldom/never). The first three items were scored on a scale of 1 to 5 , as follows: $1=$ no physical activity; $2=$ low; $3=$ medium; $4=$ medium high, $5=$ high. The mean score was defined as the overall physical activity intensity. In addition, subjects answered a fourth self perception (yes/no) item formulated by a group of three primary care physicians to resemble the question usually asked by primary care physicians in a typical anamnesis. It read as follows: Taking all your physical activities (sports, work, and leisure) in consideration, can you say that you participated in regular (habitual) physical activity? Participants who declared themselves to be physically inactive were asked to provide one or more reasons why. The main objective of item 6 was to determine reasons for conducting physical activity (not analysed here). It differed from item 4, which was included to quantify, in a subjective and relative way, the amount of physical activity.

\section{Statistical analysis}

All data were analysed with the SPSSWIN software, version 9.0lb. Data for each section were compared among the variables. The data were analysed with $\chi^{2}$ or Fisher's exact test. Comparisons of continuous data with a non-normal distribution were done with Student's $t$ test. A two tailed $\mathrm{p}$ value of 0.05 was used to define significance for differences between groups and to calculate confidence intervals. Results were considered significant when $\mathrm{p}$ was less than 0.05 . To evaluate the relation between possible different explanatory indices and the variability of the work, leisure, and sport

\begin{tabular}{|c|c|c|c|c|}
\hline $\begin{array}{l}\text { Independent } \\
\text { variables }\end{array}$ & B & $\beta$ & $\mathbf{R}$ & Significance \\
\hline Intercept & 1.41 & - & - & $<0.001$ \\
\hline Work index & 0.15 & 0.19 & 0.042 & $<0.001$ \\
\hline Sports index & 0.24 & 0.29 & 0.090 & $<0.001$ \\
\hline Symptoms & 0.02 & -0.11 & 0.012 & $<0.05$ \\
\hline
\end{tabular}

$R=r^{2}=0.16$. Variables excluded from final equation because of lack of significance at $p<0.05$ : age, sex, BMI, education, income, self perceived health status, current smoking status, and self perceived practice of regular physical activity. 
Table 3 Stepwise linear regression model of work index as dependent variable against possible explanatory variables

\begin{tabular}{llclc}
\hline Independent variables & B & B & R & Significance \\
\hline Intercept & 2.77 & - & - & $<0.001$ \\
Leisure index & 0.25 & 0.21 & 0.042 & $<0.001$ \\
Self perceived practice of regular & 0.23 & 0.14 & 0.020 & 0.004 \\
physical activity & & & & \\
Smoking & 0.22 & 0.12 & 0.017 & 0.01 \\
Education & 0.06 & -0.23 & 0.057 & $<0.001$ \\
\hline
\end{tabular}

$R=r^{2}=0.15$. Variables excluded from final equation because of lack of significance at $p<0.05$ : age, sex, BMI, income, self perceived health status, and number of disease related symptoms in the past month.

indices, three stepwise regression models were defined. The dependent variable for each model was by turn the selected index. Independent variables used in the model were all those showing a significant relation in the univariate analysis. In the models, values of negative questions were reverted.

\section{RESULTS}

All 406 subjects approached completed the questionnaire. Table 1 shows the characteristics of the study participants by physical activity variables. No significant statistical differences between men and women were detected. Younger subjects (less than 50 years) had significantly lower indices for sports and leisure. There was a significant negative correlation between body mass index (BMI), smoking, and sports index: the higher the BMI and the greater the frequency/amount of smoking, the lower the likelihood of participation in sports activities. Smoking was also positively correlated with a higher work index $(\mathrm{p}<0.002)$. Work activity level decreased with level of education, whereas sports activity increased. The sports index was also directly correlated with monthly income status: income higher than 5000 NIS (at the time of the study 4 NIS equalled US\$1.00) was associated with a significantly higher sports activity index and lower physical activity at work index. The healthier the participants felt subjectively, and the fewer symptoms they reported in the past month, the more they tended to participate in work and sports physical activities.

\section{Regression analysis (tables 2-4)}

The model used to study the dependent variable leisure index (table 2) explained $16 \%$ of the variance. In this model of the three variables entered in the last step, work index and sports index were positively correlated with leisure index, and number of symptoms was negatively correlated. Table 3 shows the model used for the dependent variable work index, which predicted about $15 \%$ of the variance. Explanatory variables entered in the last step were leisure index, self perceived practice of regular physical activity, and smoking (positive correlations), and education (negative correlation). The model for the sports index (table 4 ) explained $38 \%$ of variance. In this model, five variables were positively correlated with the dependent variable: leisure index, self perceived practice of regular physical activity, self perceived health status, age, and education.

\section{DISCUSSION}

Our findings on sex disagree with previous studies, which reported that women tend to be more sedentary than men and less likely to achieve high sport intensity scores..$^{13} 1420$ Other authors reported that women tend to participate in more moderate sports activities than men, and increase their sports activities after age 50 years. ${ }^{15}{ }^{17}$ However, all these findings have been questioned because of possible defects in the study methods. ${ }^{21}$

The model for the work index was the only one in which smoking maintained its positive correlation with physical activity after controlling for other variables. We expected a stronger negative correlation between smoking and sports and leisure indices on the basis of the well established finding that compared with their non-smoking counterparts, smokers have a reduced amount of total leisure time physical activity. ${ }^{22}$ However, this was not confirmed in our multivariate analysis. Our regression models showed that the lower the level of education, the greater the degree of physical activity at work and the lower the degree of physical sports activity. A positive correlation between more years of education and more sports activities was reported in other studies as well. ${ }^{23-25}$ On univariate analysis, we found that the higher the income, the greater the tendency to perform less physical activity at work and more at sports. Accordingly, international research studies found that blue collar employees and low income populations typically exhibit lower rates of leisure time physical activity. ${ }^{23}$ The findings among the background variables may be related, as people who are more educated tend to earn more money and to engage in occupations entailing minimal manual labour. Thus, this study, conducted in a representative randomly selected sample, together with data from previous reports, ${ }^{20-26}$ may have important implications for defining the target population for medical education for physical activities: adults between the age of 20 and 50 years of both sexes with a low

Table 4 Stepwise linear regression model of sports index as dependent variable against possible explanatory variables

\begin{tabular}{llllc}
\hline Independent variables & $\mathbf{B}$ & $\boldsymbol{\beta}$ & $\mathbf{R}$ & Significance \\
\hline Intercept constant & 0.47 & - & - & 0.032 \\
Leisure index & 0.22 & 0.18 & 0.043 & $<0.001$ \\
Self perceived practice of regular & 0.75 & 0.47 & 0.237 & $<0.001$ \\
physical activity & & & & \\
Self perceived health status & 0.10 & 0.12 & 0.210 & 0.003 \\
Age (<50 or $>50$ y) & 0.43 & 0.07 & 0.008 & 0.075 \\
Education & 0.04 & 0.14 & 0.030 & $<0.001$ \\
\hline
\end{tabular}

$R=r^{2}=0.38$. Variables excluded from final equation because of lack of significance at $p<0.05$ : Work index, age, sex, BMI, income, current smoking status, and number of disease related symptoms in the past month. 
self perceived health status and less than 13 years of education (with increasing risk with a decrease in years of education). This group, irrespective of BMI, tends to earn a comparatively low income and performs no or few leisure time activities.

It is noteworthy that this study used the Baecke questionnaire, ${ }^{12}$ a short questionnaire for the measurement of habitual physical activities in epidemiological studies. Although initially used in a Dutch population (up to age 32), other authors used the same questionnaire for the screening of physical activities of an urban adult population over age 50 years, ${ }^{15}$ much like the population in this survey.

Participants who displayed more symptoms engaged in less leisure time and sports activities (only leisure activities in the regression model), supporting the notion that sports activity has positive effects on health, or that people with fewer symptoms have fewer barriers to engage in sports and leisure activities. Analysis of the interaction among the indices showed that the performance of leisure physical activities was positively correlated with the level of activities at work and sports, and vice versa. By contrast, no correlation was found between the levels of physical activity at work and sports. These findings suggest that physicians should differentiate among the different types of physical activities (work, leisure, and sport) and their frequency and intensitydetails they often omit during anamneses because of lack of time. Usually they ask one simple question, such as "Do you practise regular physical activity?" Although our study suggests that those who answer "yes" to this question perform significantly more physical activities, the value of this indicator is questionable because it predicts only $2 \%$ of the variance in physical activities at work, $20 \%$ in sports activities, and $0 \%$ in leisure activities. Thus, the rate of regular physical activity may be even lower than suspected on the basis of self perception.

\section{Authors' affiliations}

E Kahan, Department of Family Medicine, Sackler Faculty of Medicine, Tel Aviv University, Tel Aviv, Israel

Y Fogelman, Department of Family Medicine, Leumit $\mathrm{HMO}$ and Rappaport Faculty of Medicine, Technion-Israel Institute of Technology, Haifa, Israel

B Bloch, Department of Psychiatry, HaEmek Medical Center, Afula, Israel

Funding: none.

Conflicts of interest: none declared.

\section{REFERENCES}

1 Centers for Disease Control and Prevention. Physical activity trends - United States, 1990-1998. JAMA 2001;285:1835.

2 Pomerleau J, McKee M, Robertson A, et al. Physical inactivity in the Baltic countries. Prev Med 2000;31:665-72.
3 Vaz de Almeida MD, Graca P, Afonso C, et al. Physical activity levels and body weight in a nationally representative sample in the European Union. Public Health Nutr 1999;2:105-13.

4 Robbins AS, Fonseca VP. Physical activity counseling in primary care. JAMA 2001;286:2667-8.

5 Lee IM, Sesso HD, Oguma Y, et al. Relative intensity of physical activity and risk of coronary heart disease. Circulation 2003;107:1110-16.

6 Friedenreich CM. Physical activity and cancer prevention: from observational to intervention research. Cancer Epidemiol Biomarkers Prev $2001 ; 10: 287-301$.

7 Bassett DR Jr, Fitzbugh EG, Crespo CJ, et al. Physical activity and ethnic differences in hypertension. Prevalence in the United States. Prev Med 2002;34:179-86.

8 Chakravarthy MV, Joyner MJ, Booth FW. An obligation for primary care physicians to prescribe physical activity to sedentary patients to reduce the risk of chronic health conditions. Mayo Clin Proc 2002;77:165-73.

9 Wannamethee SG, Shaper AG. Physical activity in the prevention of cardiovascular disease: an epidemiological perspective. Sports Med $2001 ; 31: 101-14$.

10 Fogelman Y, Bloch B, Kahan E. Assessment of participation in physical activities and relationship to socioeconomic and health factors. The controversial value of self-perception. Patient Education and Counseling 2004;53:95-9.

11 Caspersen CJ, Merritt RK. Physical activity trends among 26 states, 19861990. Med Sci Sports Exerc 1995;27:713-20.

12 Baecke JA, Burema J, Frijters JE. A short questionnaire for the measurement of habitual physical activity in epidemiological studies. Am J Clin Nutr 1982;36:936-42

13 Simons-Morton DG, Hogan P, Dunn AL, et al. Characteristics of inactive primary care patients: baseline data from the activity counseling trial. For the Activity Counseling Trial Research Group. Prev Med 2000;31:513-21.

14 Eyler AA, Borwnson RC, King AC, et al. Physical activity and women in the United States: an overview of health benefits, prevalence, and intervention opportunities. Women Health 1997;26:27-49.

15 Misigoj-Durakovic M, Heimer S, Matkovic BR, et al. Physical activity of urban adult population: questionnaire study. Croat Med J 2000;41:428-32.

16 Leslie E, Fortheringham MJ, Owen N, et al. Age-related differences in physical activity levels of young adults. Med Sci Sports Exerc 2001;33:255-8.

17 Livingstone MB, Robson PJ, McCarthy S, et al. Physical activity patterns in a nationally representative sample of adults in Ireland. Public Health Nutr 2001;4:1107-16.

18 Richardson MT, Ainsworth BE, Wu HC, et al. Ability of the atherosclerosis risk in communities (ARIC)/Baecke questionnaire to assess leisure-time physical activity. Int J Epidemiol 1995;24:685-93.

19 Wang L, Yamaguchi T, Yoshimine T, et al. A case-control study of risk factors for development of type 2 diabetes: emphasis on physical activity. J Epidemiol 2002:12:424-30.

20 Mullineaux DR, Barnes CA, Barnes EF. Factors affecting the likelihood to engage in adequate physical activity to promote health. J Sports $\mathrm{Sci}_{\mathrm{C}}$ $2001 ; 19: 279-88$

21 Seefeldt V, Malina RM, Clark MA. Factors affecting levels of physical activity in adults. Sports Med 2002;32:143-68.

22 Gardner AW, Womack CJ, Montgomery PS, et al. Cigarette smoking shortens the duration of daily leisure time physical activity in patients with intermittent claudication. Journal of Cardiopulmonary Rehabilitation 1999;19:43-51.

23 Taylor WC, Baranowski T, Young DR. Physical activity interventions in lowincome, ethnic minority, and populations with disability. Am J Prev Med 1998; 15:334-43

24 Iwai N, Yoshiike N, Saitoh S, et al. Leisure-time physical activity and related lifestyle characteristics among middle-aged Japanese. Japan Lifestyle Monitoring Study Group. J Epidemiol 2000;10:226-33.

25 Burton NW, Turrell G. Occupation, hours worked, and leisure-time physical activity. Prev Med 2000;31:673-81.

26 Lakka TA, Kauhanen J, Salonen JT. Conditioning leisure time physical activity and cardiorespiratory fitness in sociodemographic groups of middle-aged men in eastern Finland. Int J Epidemiol 1996;25:86-93. 